Please do not remove this page

RMIT

UNIVERSITY

\title{
The impact of temperature on the rheological behaviour of anaerobic digested sludge
}

Baudez, Jean; Slatter, Paul; Eshtiaghi, Nicky

https://researchrepository.rmit.edu.au/esploro/outputs/9921859194301341/filesAndLinks?institution=61RMIT_INST\&index=null

Baudez, J., Slatter, P., \& Eshtiaghi, N. (2013). The impact of temperature on the rheological behaviour of anaerobic digested sludge. Chemical Engineering Journal, 215-216, 182-187.

https://doi.org/10.1016/j.cej.2012.10.099

Published Version: https://doi.org/10.1016/j.cej.2012.10.099

Repository homepage: https://researchrepository.rmit.edu.au

(c) 2012 Elsevier B.V. All rights reserved.

Downloaded On 2023/04/27 00:58:24 +1000

Please do not remove this page 
Thank you for downloading this document from the RMIT Research Repository.

The RMIT Research Repository is an open access database showcasing the research outputs of RMIT University researchers.

RMIT Research Repository: http://researchbank.rmit.edu.au/

\section{Citation:}

Baudez, J, Slatter, P and Eshtiaghi, N 2013, 'The impact of temperature on the rheological behaviour of anaerobic digested sludge', Chemical Engineering Journal, vol. 215-216, pp. 182-187.

See this record in the RMIT Research Repository at:

http://researchbank.rmit.edu.au/view/rmit:18284

Version: Accepted Manuscript

Copyright Statement: (c) 2012 Elsevier B.V. All rights reserved.

Link to Published Version:

http://dx.doi.org/10.1016/j.cej.2012.10.099

\section{PLEASE DO NOT REMOVE THIS PAGE}



2 Rheology and Materials Processing Centre, Dept. of Chemical Engineering, RMIT University, Victoria, Australia, 3001

Corresponding author: jean-christophe.baudez@irstea.fr

Abstract

The rheological properties of municipal anaerobic digested sludge rheology are temperature dependent. In this paper, we show that both solid and liquid characteristics decrease with temperature. We also show that the yield stress and the high shear (Bingham) viscosity are the two key parameters determining the rheological behaviour. By normalising the shear stress with the yield stress and the shear rate with the yield stress divided by the Bingham viscosity, a master curve was obtained, independent of both temperature and concentration. We also show that the rheological behaviour is irreversibly altered by the thermal history. Dissolution of some of the solids may cause a decrease of the yield stress and an increase of the Bingham viscosity. This result suggests that the usual laws used to describe the thermal evolution of the rheological behaviour of fluids are no longer valid with anaerobic digested sludge. Finally, the impact of temperature and thermal history have to be taken into account for the design of engineering hydrodynamic processes such as mixing and pumping.

Keywords stress 
Introduction

4 Anaerobic digestion is one of the most important processes for reducing sludge volume by

5 reducing of about $30 \%$ of the organic load (part of the solid organic matter is converted into gas)

6 and for producing biogas. To be efficient, anaerobic digestion needs to satisfy at least three

7 conditions: (i) controlled temperature, between 35 and $37^{\circ} \mathrm{C}$ for mesophilic processes or between

855 and $58^{\circ} \mathrm{C}$ for thermophilic processes, (ii) homogeneous mixing conditions and (iii) no dramatic

9 variation in organic load. To control temperature, biogas is partly used for heating large digesters through heat exchangers installed in recirculation loops (Gerardi, 2003). If possible sludge also has to be initially pre-heated to the appropriate temperature and raw sludge is sometimes mixed with digested sludge before entering the digester (Keeper, 1959). In other cases, the digester mixing system ensures that the cold, newly introduced sludge, is mixed with the warm older solids and the bacteria. Finally, the entire digester volume needs to be turned over once every $3-4$ hours (Slatter, 2011).

Because flow velocities within the digester and the recirculation loops are not of the same order of magnitude, a better understanding of the rheological properties of digested sludge over a wide showed that anaerobic digested sludge rheology can be described using the Herschel-Bulkley model, for which the rheological characteristics decreased with the degree of fermentation. More recently, Baudez et al. (2011a) highlighted a more complex behaviour with shear banding at low shear rates and a viscosity plateau at very high shear rates. However, these studies did not focus on the temperature dependence of the rheology of digested sludge, which would fundamentally affect the flow properties and consequent operating conditions of the digester.

Since the pioneering work of Manoliadis and Bishop (1984) who pointed out a decrease of rheological characteristics similar to what is usually observed with Newtonian fluids, there is very little literature on the impact of temperature on municipal sludge rheology. In a recent paper, 
1 Baudez et al. (2011b) showed that the decrease of viscoelastic properties is proportional to the decrease of water viscosity with increase in temperature, suggesting thermal motion may be the key factor, in agreement with what was observed by Manoliadis and Bishop (ibid.) while DieudeFauvel et al. (2009) considered a VTF model (Vogel-Tamman-Fulcher) on secondary sludge. However, because municipal sludge in mainly composed of water, mineral particles and organic matter (polymeric and dissolved), one can imagine that the temperature dependence of sludge would be similar to what it is observed with mineral suspensions and organic polymers. If there is a general agreement in polymer science to consider that temperature decreases rheological characteristics, de Kretser and Scales (2008) showed that the solid characteristics of mineral suspensions can increase with an increase of temperature while liquid characteristics decrease. In this paper, we revisit the temperature dependence of digested sludge, both in the liquid and the solid regimes and we propose that thermal motion has the most important impact. We also show that it is not the only mechanism impacting sludge rheology. Similarities between the rheological behaviour of digested sludge at different temperatures were found, but temperature also irreversibly modified sludge structure. After being heated and cooled down, digested sludge showed a lower yield stress but a higher consistency index than the initial material, at the same temperature. Apart from the fundamental contribution this makes to understanding sludge behaviour, such behaviour has to be taken into account for the practical design and operation of anaerobic digesters, especially heat exchangers and pipe flow.

Material and methods a cylinder onto a filter paper and vacuum suction was applied at the pressure of -0.5 bars. During all the filtration process, sludge was softly mixed to let the solid particles in suspension, avoiding clogging of the filter paper. Solid concentration was determined by drying the sludge at $105^{\circ} \mathrm{C}$ for 24 hours. 
Because fermentation alters sludge rheological characteristics mainly in the first 10 days of storage (Baudez and Coussot, 2001), and although anaerobic digestion is a stabilization process, our samples were stored at $4^{\circ} \mathrm{C}$ for 30 days before experiments, to ensure no temporal variability, allowing us to use the same material over several days. This technique was successfully used by

5 Curvers et al. (2009).

Rheological measurements were performed with a stress-controlled DSR200 from Rheometric Scientific, connected to a temperature controlled water bath. The rheometer was equipped with a cup and bob geometry (inner diameter: $29 \mathrm{~mm}$, outer diameter: $32 \mathrm{~mm}$, length: $44 \mathrm{~mm}$ ). In order to highlight its impact on the rheological behaviour of digested sludge, temperature was varied from

1110 to $80^{\circ} \mathrm{C}$ using a temperature controlled water bath. To avoid evaporation, sludge was covered with a thin film of Newtonian oil (oil and sludge are not miscible, as evidenced by oil removal processes in wastewater treatment plants).

Before each measurement, the sludge was presheared for 10 minutes at a shear rate of $1000 \mathrm{~s}^{-1}$ then left at rest for 10 minutes before each measurement. With such a procedure, measurements were repeatable and reproducible (Baudez and Coussot, 2001; Baudez et al., 2011a). Because of shear banding, direct determination of the yield stress has to be conducted with It must be noted that what will be called yield stress in the following should be seen as the extrapolation of the flow curve towards zero shear rate: it basically represents the limit below which there is no steady state flow. 
1 Lastly, all the data fits shown in this paper were obtained using Excel software and its solver macro based on the "least squares" difference between model and experiment.

3

4 Definition of the general behaviour of anaerobic digested sludge

5 The following results will be interpreted according to the behaviour of digested sludge determined 6 by Baudez et al. (2011a):

7 - a linear viscoelastic behaviour in the solid regime, well represented by a generalised Kelvin-Voigt 8 model, with a wide relaxation times spectrum modelled by a stretched exponential:

$9 \quad \gamma(t)=\tau \cdot \frac{1}{G} \cdot\left(1-\exp \left(-(\lambda t)^{m}\right)\right)$

10 where $\gamma$ represents the strain, $\tau$ the stress and $\lambda=\frac{G}{\mu}$ with $G$ (representative of the purely

11 elastic spring) and $\mu$ (representative of the purely viscous damper) the usual parameters of a 12 Kelvin-Voigt model.

13 - a shear-thinning behaviour with a constant high-shear viscosity in the liquid regime, well 14 represented by a Herschel-Bulkley model coupled with a Bingham model (Baudez et al., 2011a):

$$
\begin{aligned}
& \tau=\tau_{c}+K \cdot \dot{\gamma}^{n}+\alpha_{0} \cdot \dot{\gamma} \\
& \Leftrightarrow \frac{\tau}{\tau_{c}}=1+\frac{K}{\tau_{c}} \cdot \dot{\gamma}^{n}+\frac{\alpha_{0}}{\tau_{c}} \cdot \dot{\gamma} \\
& \Leftrightarrow \frac{\tau}{\tau_{c}}=1+\xi \cdot \Gamma^{n}+\Gamma \\
& \Gamma=\frac{\alpha_{0}}{\tau_{c}} \cdot \dot{\gamma}, \xi=\frac{K}{\tau_{c}} \cdot\left(\frac{\tau_{c}}{\alpha_{0}}\right)^{n}
\end{aligned}
$$

where $\tau_{c}$ represents the extrapolated limit below which there is no steady-state flow (improperly named yield stress in the following), $K$ the consistency index, $\alpha_{0}$ the high shear viscosity rate 18 (named Bingham viscosity in the following) and $n$ the power-law index. Note that such a 19 dimensionless form was previously used by Coussot (1995) with mineral suspensions. It comes from from the identical shape of the flow curves. Thus, it is natural to scale the shear stress by the 21 yield stress, such that all curves go through the same point $\left(\gamma=0 ; \tau_{e}=1\right)$. This means we probably smooth the solid interactions since $\tau_{\widetilde{\sigma}}$ represents the strength of particle interactions 'at rest'. In parallel it is necessary to scale the shear rate by a factor also related to viscous 
dissipation. This may be done by assuming that for high shear rates the energy dissipation resulting from interactions between solid particles becomes negligible compared to hydrodynamic dissipation. Under these conditions, like Coussot (1995) did for mineral suspensions, it is natural to

4 use a dimensionless number, $\Gamma$ defined as $\Gamma=\frac{\mu}{\tau_{c}} \cdot \dot{\gamma}$ where $\mu$ is the viscosity of the equivalent 5 suspension of force-free particles in water. Following the work of Quemada (1998), we assumed that at high shear particles are independent of each others, so $\mu=\alpha_{0}$.

8 Results and discussion

9 The impact of temperature on the solid characteristics

11 First focusing on increasing shear stress sweep, the model defined by Eq (1) is accurate at low shear stress (fig. 1), and the higher the temperature, the higher the shear strain at a given shear stress (fig. 1). Only the elasticity appears to change significantly with the temperature (Table 1), and its changes with temperature are proportional to those of water viscosity (Fig. 2), indicating that there are probably the same molecular movements which are involved in both water viscosity and elastic coefficient changes with the temperature.

Table 1: Values of the viscoelastic parameters given by Eq (1) at different temperatures.

\begin{tabular}{|l|l|l|l|l|}
\hline & $10^{\circ} \mathrm{C}$ & $25^{\circ} \mathrm{C}$ & $40^{\circ} \mathrm{C}$ & $60^{\circ} \mathrm{C}$ \\
\hline $\mathrm{G} / 100[\mathrm{~Pa}]$ & 0.559 & 0.385 & 0.263 & 0.167 \\
\hline$\lambda\left[\mathrm{t}^{-\mathrm{n}}\right]$ & 1.488 & 1.489 & 1.489 & 1.499 \\
\hline $\mathrm{n}[1]$ & 0.416 & 0.421 & 0.374 & 0.479 \\
\hline
\end{tabular}

The constant value of the parameter $\lambda$ also indicated that both the elastic and viscous characteristics of the Kelvin-Voigt model follow the same relationship regarding temperature., mainly caused by thermal agitation (due to the proportionality with water viscosities). 
1 The same temperature evolutions are observed with the flow curves, in the liquid regime (fig. 3):

2 the higher the temperature, the higher the shear rate (and so, the lower the apparent viscosity) at a

3 given shear stress. Sludge becomes less and less viscous as the temperature increases.

4 In the dimensionless form of (2), all the flow curves resolve to a single master curve, independent

5 of both temperature and concentration (fig. 4), indicating that the (extrapolated) yield stress and the

6 Bingham viscosity are the two key parameters to characterise the flowing behaviour of digested

7 sludge. Note that the consistency index $K$ appears to be proportional to $\tau_{c}$ (data not shown) but

8 at this stage, we have no explanation for that.

9 Moreover, in the temperature range of $\left[10-60^{\circ} \mathrm{C}\right]$, both the yield stress (fig. 5) and the Bingham 10 viscosity decreased, this latter followed a linear relationship with water viscosity (fig. 6), meaning

11 thermal agitation also had a major influence in the change of the liquid characteristics. Surprisingly, the temperature changes of $\tau_{c}$ are not proportional to the water viscosity changes, which could have been expected because of the impact of temperature on the elasticity. This probably comes from the determination of $\tau_{c}$ which is not a 'real' rheological characteristic but rather a fitting parameter (due to shear banding, $\tau_{c}$ cannot be measured directly).

Following the results of Rodd et al. (2001), Baudez (2008) and Baudez et al. (2011a), the yield stress and the Bingham viscosity can be expressed as follows:

where $\phi_{0}$ is the lowest concentration below which there is no yield stress (also called gel point in polymer science), $m$ is a parameter which can be related to the fractal dimension of sludge flocs (Pignon et al., 1996), $\mu_{0}$ is the viscosity of the liquid medium, and $a$ and $\beta$ are model parameters.

From the fitted values of $\tau_{c}$ and $\alpha_{0}$ (see appendix for all the rheological values), we have determined the numerical values for the parameters of (3) and (4): $\mu_{0}$ and $\beta$ of (4) and $a$ and $m$ of (3) decreased when the temperature increased while $\phi_{0}$ increased (fig. 7 and table 2)). 
Table 2: Values of parameters of (3) and (4) at different temperatures.

\begin{tabular}{|l|l|l|l|l|}
\hline & $10^{\circ} \mathrm{C}$ & $25^{\circ} \mathrm{C}$ & $40^{\circ} \mathrm{C}$ & $60^{\circ} \mathrm{C}$ \\
\hline$\phi_{0}[\%]$ & 0.787 & 0.792 & 0.825 & 0.948 \\
\hline$a[\mathrm{~Pa}]$ & 0.0855 & 0.0817 & 0.0803 & 0.0654 \\
\hline$m[1]$ & 2.482 & 2.366 & 2.352 & 2.153 \\
\hline$\mu_{0}[\mathrm{mPa} . \mathrm{s}]$ & 1.826 & 1792 & 1.777 & 1.762 \\
\hline$\beta[1]$ & 0.6935 & 0.605 & 0.517 & 0.426 \\
\hline
\end{tabular}

3 Assuming that $m$ reflects the fractal dimension of the flocs (Pignon et al., 1996), its decrease

4 means that the flocs became less dense and compact (Li and Ganczarczyk, 1989). From a more

5 fundamental perspective, this also means that if flocs are seen as spherical agglomerates of 6 particles, the decrease in fractal dimension implies that (i) floc surface remained constant while the number of voids increased or (ii) floc surface increased. In both cases, it would mean that sludge structure is modified when the temperature increases..

The impact of thermal history

11 If sludge is heated and cooled before measurement, its rheological behaviour is irreversibly altered 12 compared to its initial behaviour with no such thermal history (fig. 8): the hotter the preheat, the smaller the yield stress and the higher the Bingham viscosity (fig. 9), the consistency being almost constant. This result strengthened the assumption we previously made and it also indicated that the structural changes induced by an increase of temperature are globally irreversible. At this time, it must be strongly emphasised that our initial anaerobic digested sludge was picked up at the outlet of a mesophilic digester which runs between 35 and $38^{\circ} \mathrm{C}$. So our results obtained at the temperature below the digester operating temperature were already influenced by the previous thermal history of the sludge. That's may explain why the variation of the rheological characteristics are weak below $40^{\circ} \mathrm{C}$ and also why there is no significant change in fig. 6 between

2125 and $40^{\circ} \mathrm{C}$ : in this range, the yield stress and the water viscosity appear to be proportional (data not shown), suggesting that (i) thermal fluctuation is the main factor responsible of the yield stress decrease below $40^{\circ} \mathrm{C}$ and (ii) the alteration of the composition with the temperature is irreversible. 
However, by reducing shear rate and shear stress to dimensionless form as proposed in Eq(2), a master curve was also obtained (fig. 10), indicating that ultimately the yield stress and the Bingham viscosity can again be considered as the two key parameters which drive the rheological behaviour of anaerobic digested sludge and its (physical) evolution with temperature.

6 As suggested above, thermal history apparently irreversibly modified the structural characteristics of the sludge, because of the change of the rheological characteristics, but did not change the total solid concentration. Indeed, we did not find significant changes in the total solid concentration regarding temperature history, which is quite logical in the sense that water content determination 10 imply to heat sludge at a higher temperature that we did. So, assuming the total solids

11 concentration was kept constant by preheating the sludge, from Eq (4), we can deduce the increase of Bingham viscosity originates only from an increase in $\mu_{0}$ (since $\beta$ decreases with temperature) and in parallel, the yield stress decreases. Keeping in mind that the fractal dimension of the flocs decrease with the temperature, if the viscosity of the medium increased while the yield stress decreased, it implies that there is a transfer from solids constituents to dissolved constituents, the total solids concentration being constant. This assumption has to be confirmed, by measuring the liquor viscosity before and after heating. However such a result was already reported by Appel et al. (2010) who pointed out that temperature increase promoted dissolution of the main organic (proteins, carbohydrates and volatile fatty acids) and inorganic (heavy metals, S and P) sludge constituents. Paul et al. (2006) suggested a preferential dissolution of proteins over carbohydrates by measuring COD released after thermal treatment of digested sludge.

Because material composition changed with temperature, it is then quite impossible to define temperature evolution laws with consistent physical meaning for parameters from Eqns (3) and (4): it would be fundamentally inaccurate to consider constant activation energies, as the composition is changing with temperature.

Conclusion

29 The impact of temperature on the rheological behaviour of digested sludge has been investigated. 
1 the shear stress with the yield stress and the shear rate with the yield stress divided by the

2 Bingham viscosity, a master curve was obtained. Both yield stress and Bingham viscosity

3 decreased with increasing temperature, indicating that thermal agitation had a major influence.

4 However, it is not the only parameter influencing the fluidisation of sludge: thermal history also

5 played an important role.

6 If sludge was preheated and cooled before experiment, the initial yield stress decreased while

7 initial Bingham viscosity increased: this may result from a conversion of solid to dissolved

8 constituents, a process which is partially irreversible. Thus, the usual laws used to model

9 temperature dependence would be no longer valid because such laws can only be used when the

10 composition remains constant. This point cannot be asserted in the case of anaerobic digestion

11 sludge as our results suggest that the sludge composition may be altered by temperature. In order

12 to confirm this assumption, further work is needed to measure liquor viscosity by filtering sludge at

13 different temperatures. The apparatus to enable such an experiment is under construction.

14 Such behaviour has to be taken into account in the hydrodynamic modelling of industrial flow 15 processes in which temperature is modified, such as in recirculation loops through sludge heaters, 16 where head loss determination can be significantly affected.

Acknowledgements

The authors gratefully acknowledge Irstea, Melbourne Water and South East Water (Ltd.) as well as the Research and Innovation Office of RMIT University for providing support for Dr JeanChristophe Baudez's visit to pursue this research

References

Appels L, Degrève J, Van der Bruggen B, Van Impe J, Dewil R, 2010. Influence of low temperature thermal pre-treatment on sludge solubilisation, heavy metal release and anaerobic digestion. Bioressour. Technol., 101 (15), pp. 5743-5748 
1 Baudez, J.C., Coussot, P., 2001. Rheology of aging, concentrated, polymeric suspensions -

2 Application to pasty sewage sludges. J. Rheol. 45(5):1123-1139.

3 Baudez, J.C., Gupta, R.K., Eshtiaghi, N., Parthasarathy, R., Slatter, P., 2011b. Digested sludge rheology: similarities with soft glassy materials. Chemeca conference, Sydney, Australia.

5 Baudez, J.C., Markis, F., Eshtiaghi, N., Slatter, P., 2011a. The rheological behaviour of digested 6 sludge. Water Research, 45, 17, 5675-5680.

7 Curvers, D., Saveyn, H., Scales, P.J., Van der Meeren, P., 2009. A centrifugation method for the assessment of low pressure compressibility of particulate suspensions. Chemical Engineering Journal Volume 148, Issue 2-3, 15 May 2009, Pages 405-413 de Kretser, R.G., Scales, P., 2008. The effect of temperature on the yield stress of mineral suspensions, Journal of Colloid and Interface Science, Volume: 328, Issue: 1, Pages: 187-193 Dieudé-Fauvel, E., VanDamme, H., Baudez, J.C., 2009. Improving rheological sludge characterization with electrical measurements. Chemical Engineering Research and Design. 87, 982-986

Gerardi, M.H., 2003. The microbiology of anaerobic digesters. Wiley and Sons Eds.

Keeper, C.E., 1959. Effect on premixing raw and digested sludge on high-rate digestion. Sewage and industrial wastes, 31, 4, 388-398.

Li D, Ganczarczyk J:1989. Fractal geometry of particle aggregates generated in water and wastewater treatment processes. Environ. Sci. Technol. 23 1385-1389. Manoliadis, O., Bishop, P.L., 1984. Temperature effect on rheology of sludges. Journal of Environmental Engineering, Volume 110, Issue 1, February 1984, Pages 286-290 Monteiro, P.S., 1997. The influence of the anaerobic digestion process on the sewage sludges and Technology, 54 (5), pp. 59-68 Pignon F, Piau JM, Magnin A., 1996. Structure and pertinent length scale of a discotic clay gel. Phys. Rev. Lett. 76, 4857-4860 Quemada, D., 1998. Rheological modelling of complex fluids. The concept of effective volume fraction revisited. The European Physics Journal AP, 1, 119-127. 
1 Rodd, A. B., Cooper-White, J. J., Dunstan, D. E. and Boger, D. V., 2001. Polymer concentration

2 dependence of the gel point for chemically modified biopolymer networks using small amplitude

3 oscillatory rheometry. Polymer, 42 8: 3923-3928.

4 Slatter P. T. 2011, The Engineering Hydrodynamics Of Viscoplastic Suspensions. J. Particulate

5 Science and Technology, 29: 2, 139-150.

6

Appendix : numerical values of rheological characteristics allowing us to plot the master curve

8

\begin{tabular}{|c|c|c|c|c|}
\hline & $10^{\circ} \mathrm{C}$ & $25^{\circ} \mathrm{C}$ & $40^{\circ} \mathrm{C}$ & $60^{\circ} \mathrm{C}$ \\
\hline & \multicolumn{4}{|c|}{$18.5 \mathrm{~g} \cdot \mathrm{L}^{-1}$} \\
\hline$\tau_{\mathrm{c}}$ & 0.100 & 0.092 & 0.088 & 0.052 \\
\hline $\mathrm{K}$ & 0.194 & 0.169 & 0.148 & 0.097 \\
\hline $\mathrm{n}$ & 0.308 & 0.308 & 0.308 & 0.308 \\
\hline \multirow[t]{2}{*}{$\alpha_{0}$} & 0.007 & 0.005 & 0.004 & 0.003 \\
\hline & \multicolumn{4}{|c|}{$25.5 \mathrm{~g} \cdot \mathrm{L}^{-1}$} \\
\hline$\tau_{\mathrm{c}}$ & 0.335 & 0.293 & 0.201 & 0.146 \\
\hline $\mathrm{K}$ & 0.531 & 0.436 & 0.331 & 0.240 \\
\hline $\mathrm{n}$ & 0.308 & 0.308 & 0.308 & 0.308 \\
\hline \multirow[t]{2}{*}{$\alpha_{0}$} & 0.012 & 0.009 & 0.008 & 0.006 \\
\hline & \multicolumn{4}{|c|}{$32.5 \mathrm{~g} \cdot \mathrm{L}^{-1}$} \\
\hline$\tau_{\mathrm{c}}$ & 0.711 & 0.711 & 0.606 & 0.376 \\
\hline $\mathrm{K}$ & 0.976 & 0.905 & 0.770 & 0.499 \\
\hline $\mathrm{n}$ & 0.308 & 0.308 & 0.308 & 0.308 \\
\hline \multirow[t]{2}{*}{$\alpha_{0}$} & 0.016 & 0.013 & 0.011 & 0.008 \\
\hline & \multicolumn{4}{|c|}{$49.0 \mathrm{~g} \cdot \mathrm{L}^{-1}$} \\
\hline$\tau_{\mathrm{c}}$ & 2.844 & 2.300 & 2.175 & 1.255 \\
\hline $\mathrm{K}$ & 3.686 & 2.769 & 2.327 & 1.383 \\
\hline $\mathrm{n}$ & 0.308 & 0.308 & 0.308 & 0.308 \\
\hline
\end{tabular}




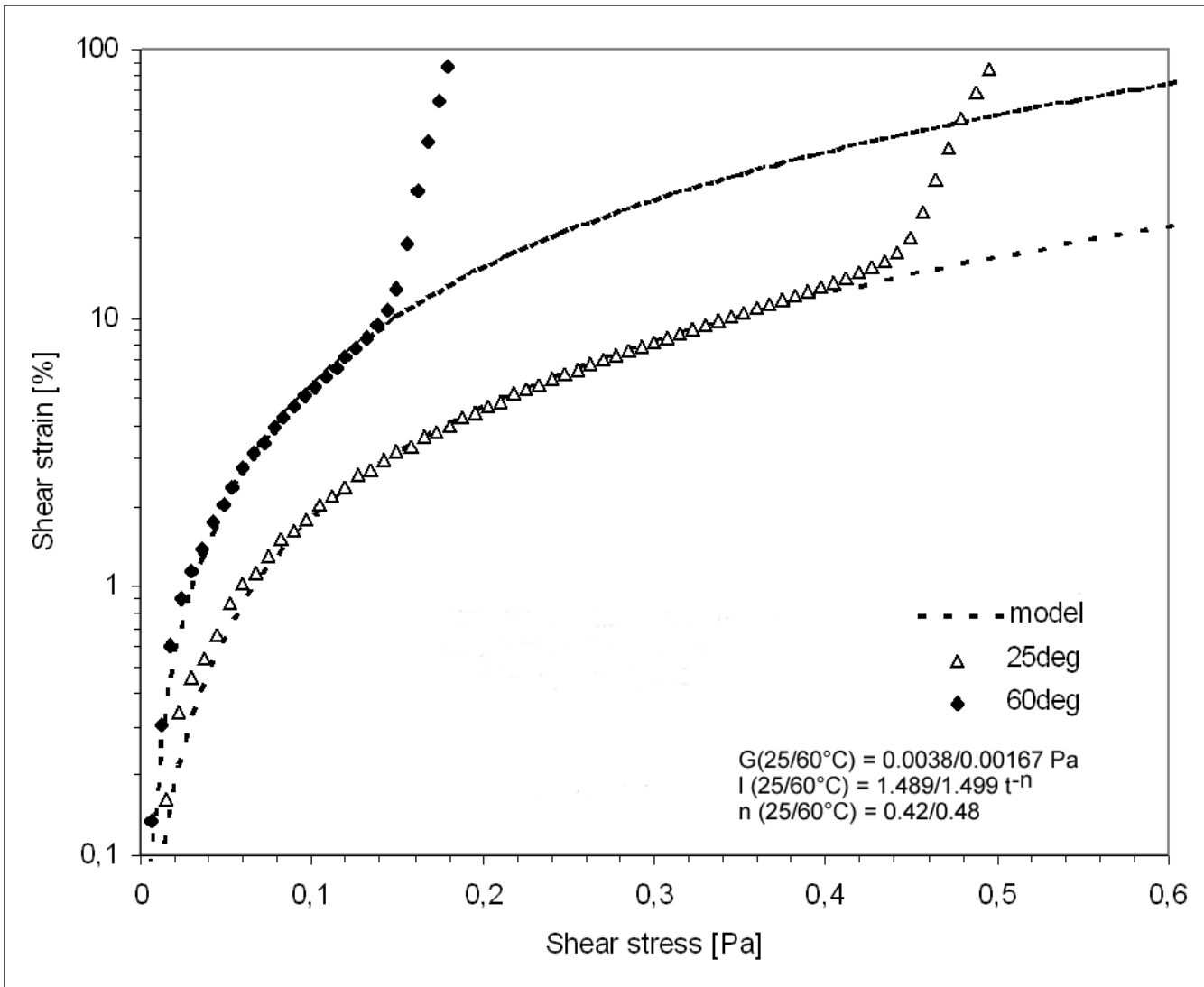

Figure 1: Viscoelatic behaviour of the $4.8 \%$ sludge. at 25 and $60^{\circ} \mathrm{C}$. The dotted lines represent the fit of the generalised Kelvin-Voigt model Equation (1) 


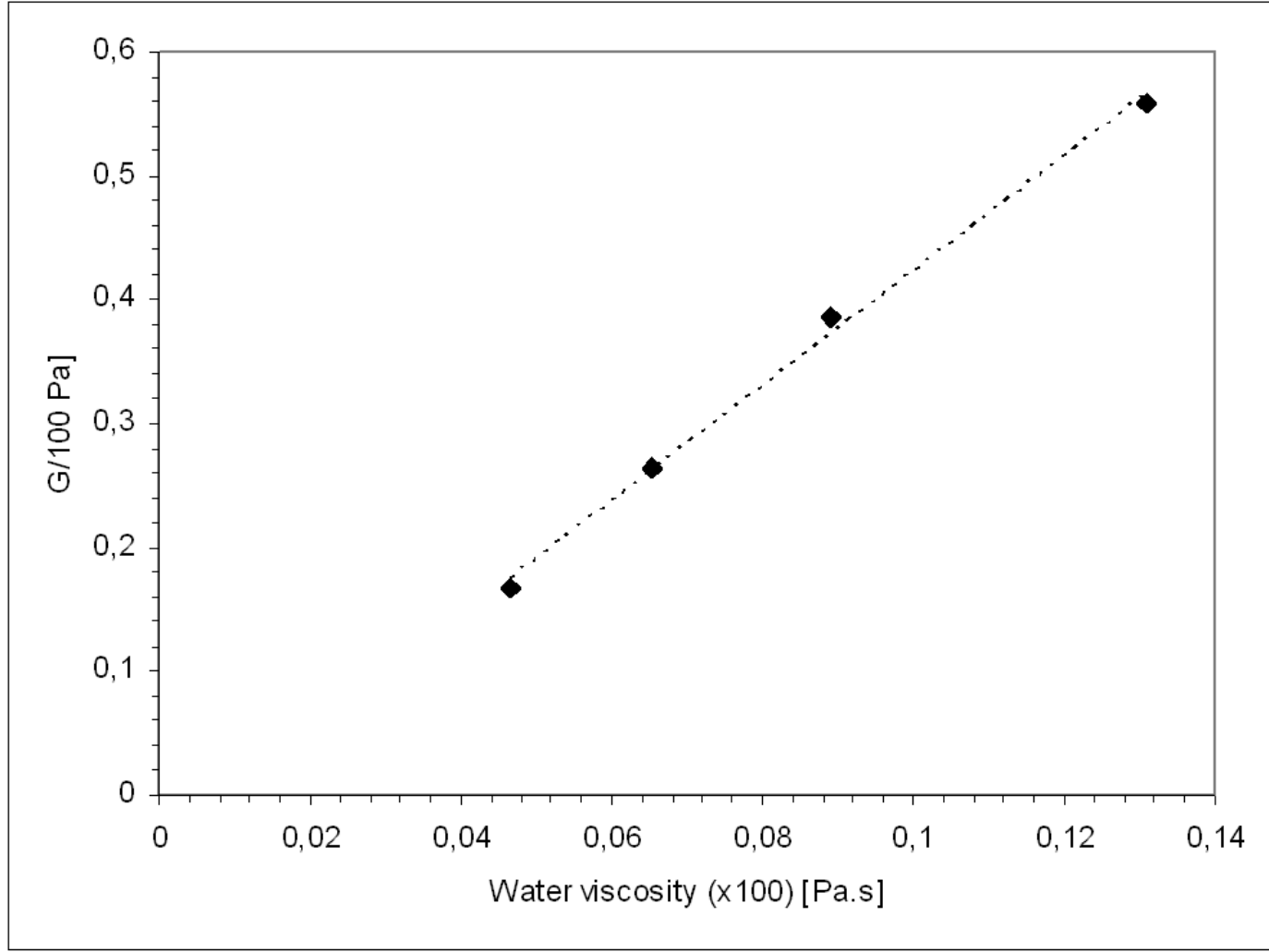

Figure 2: Linear relationship between the elastic coefficient and water viscosity 


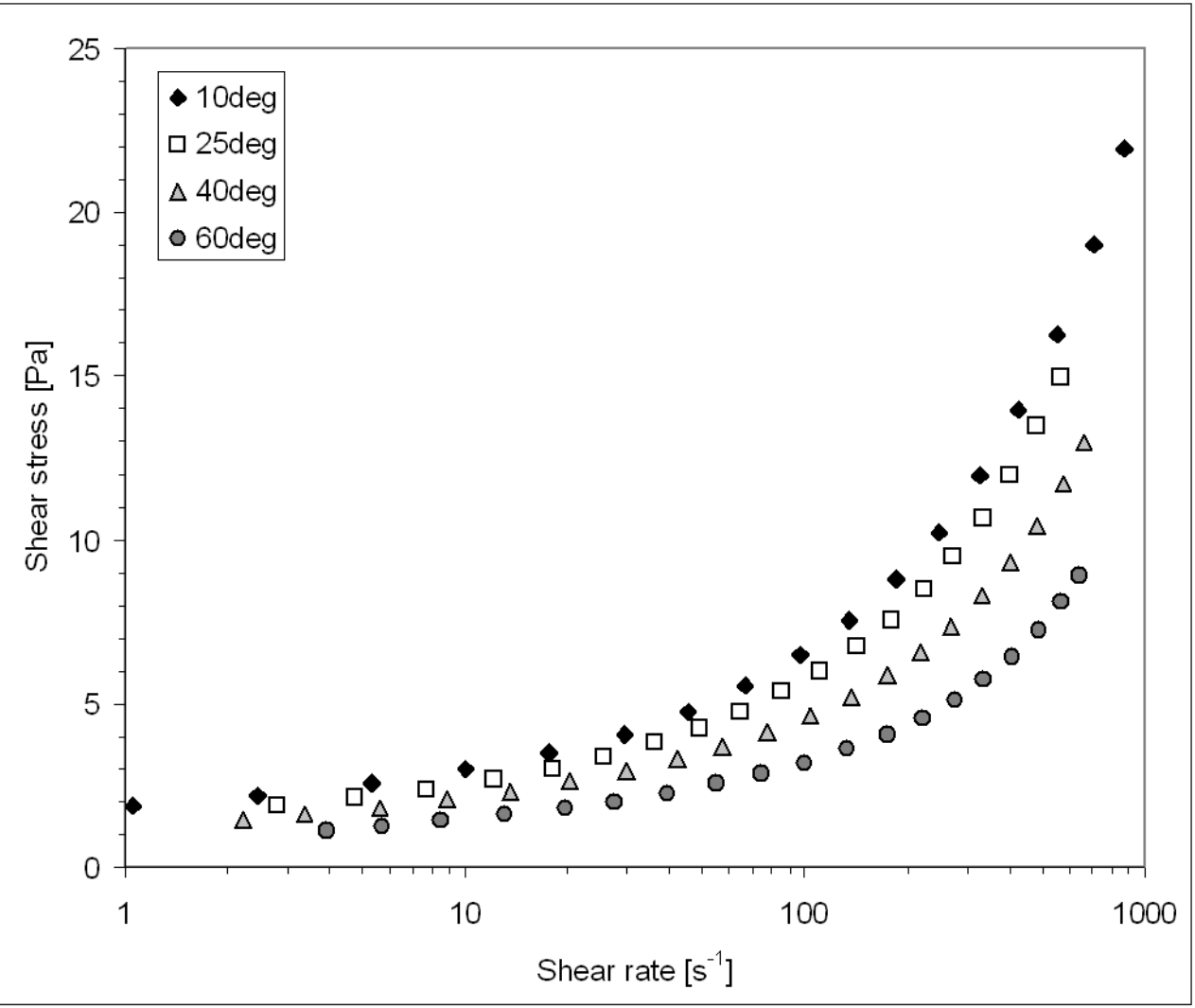

Figure 3: Flow curves of the $3.2 \%$ digested sludge at different temperatures. 


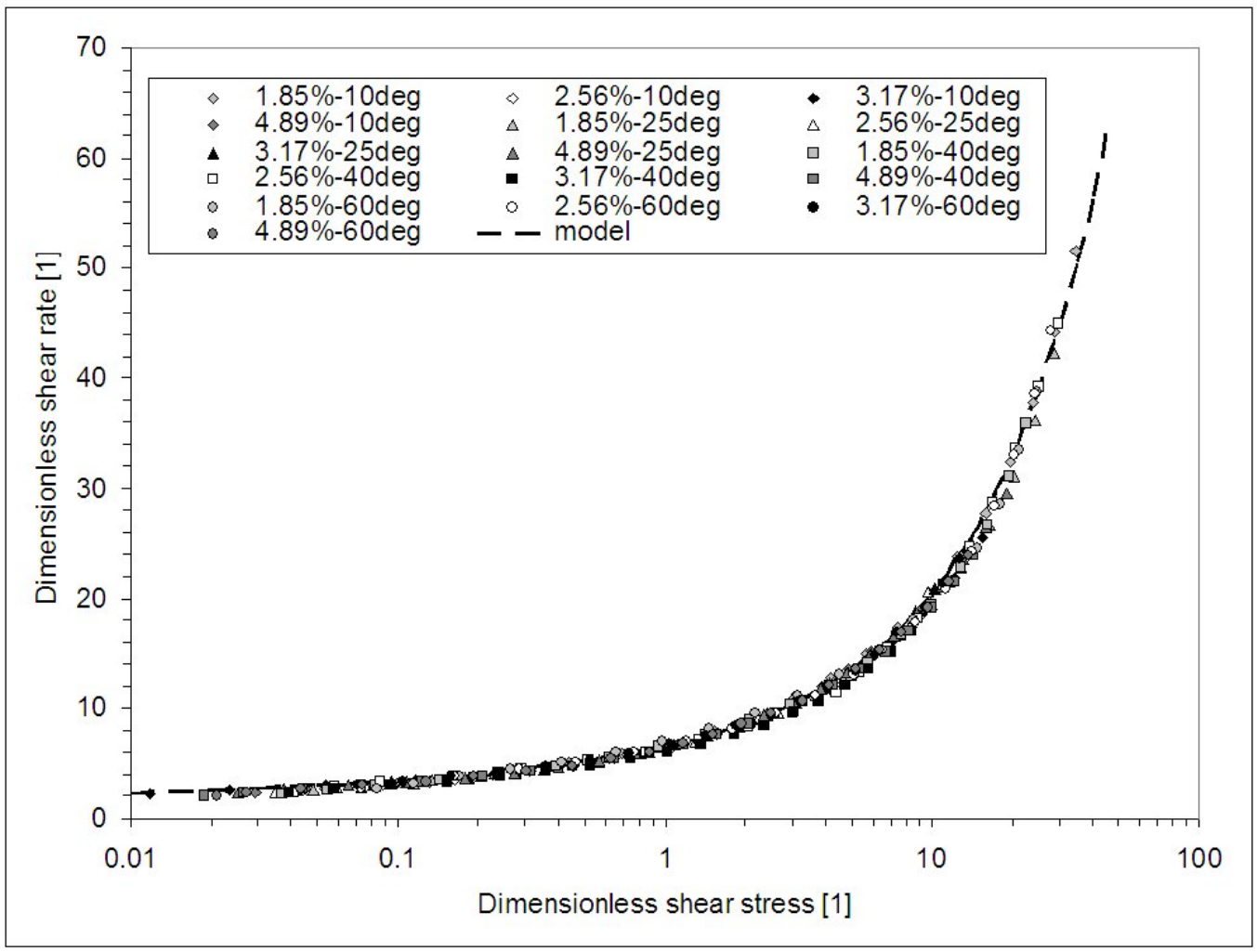

Figure 4: Dimensionless flow curves of the digested sludge at different solids concentration and temperature. The dotted line represents the model of Equation (2) with the following parameters:

$$
\xi=4.57, n=0.3
$$




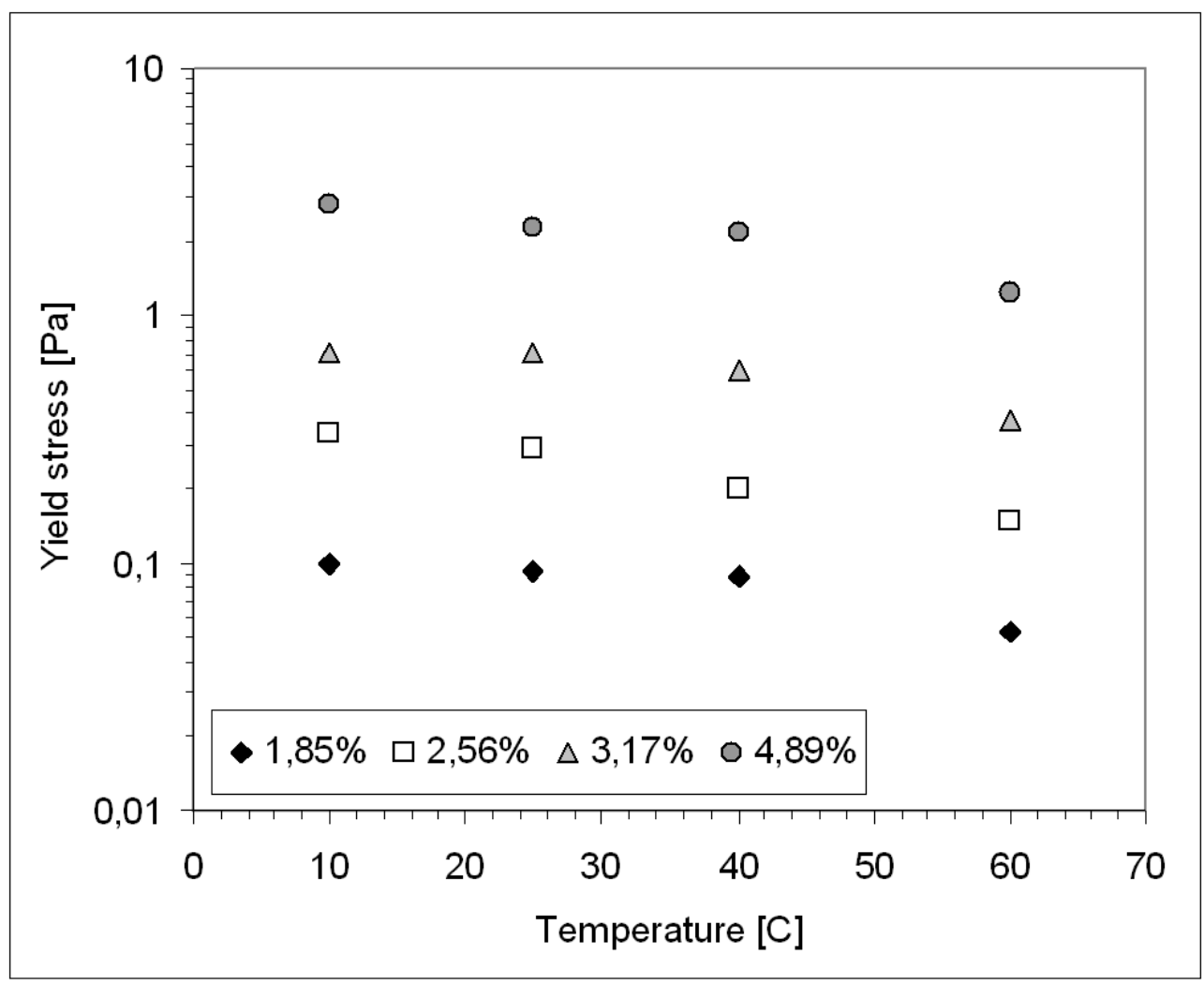

Figure 5: Evolution of the yield stress with temperature for the digested sludge at different 3 concentrations.

4

5 


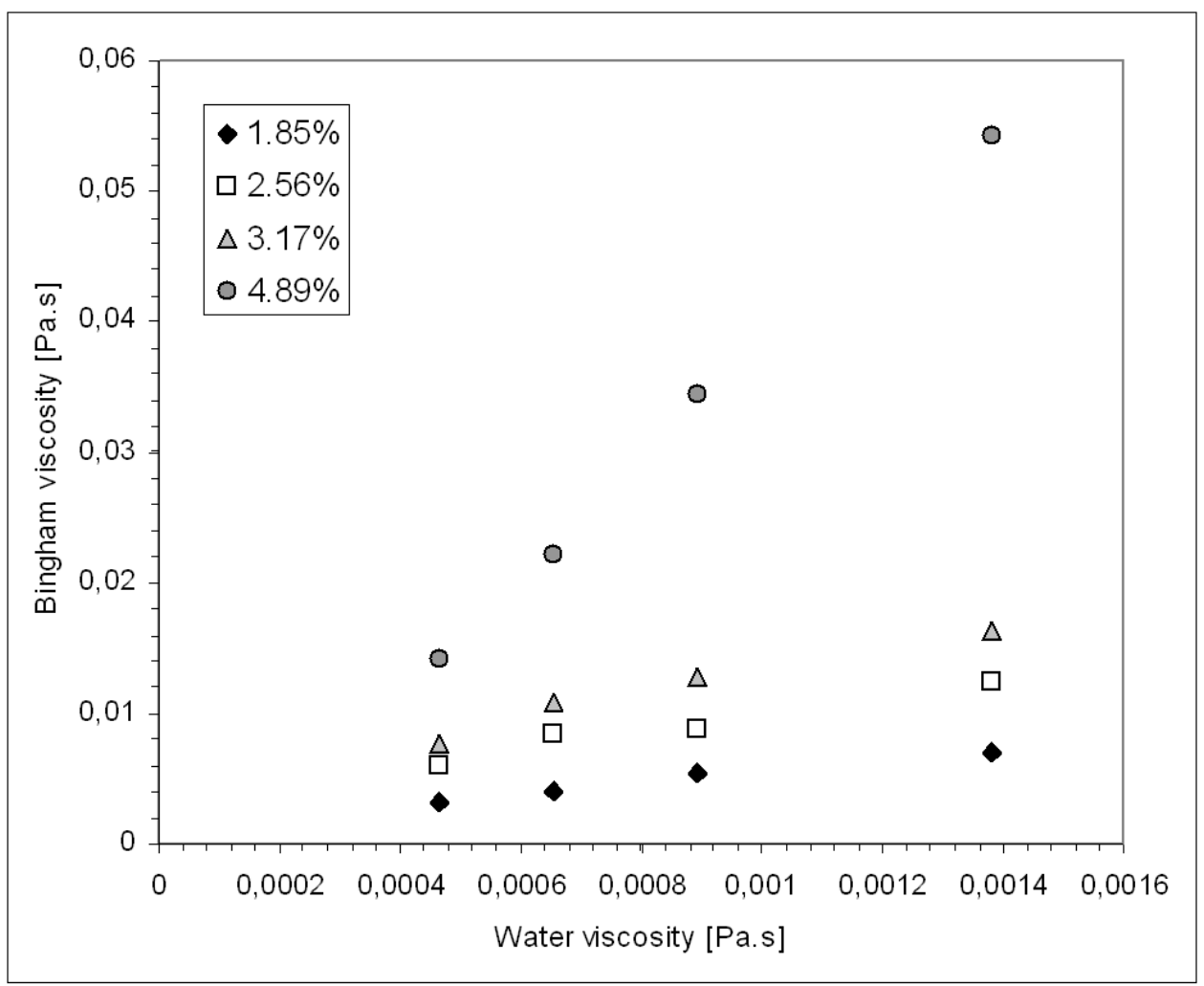

Figure 6: Thermal evolution of the Bingham viscosity of the digested sludge at different concentrations plotted against the viscosity of water at the same temperatures.

4

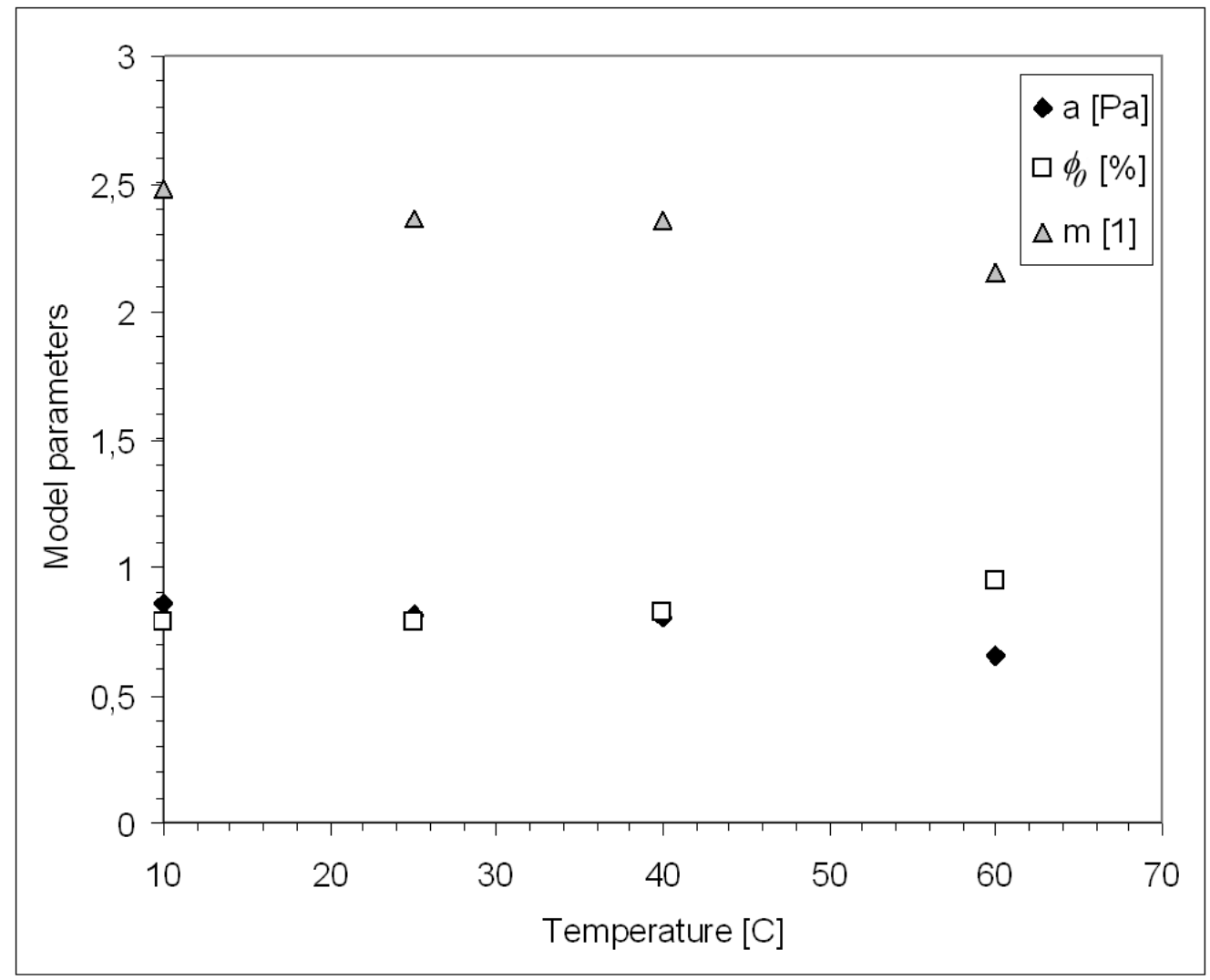

Figure 7: Evolution of the parameters of Equation (3) with temperature. 


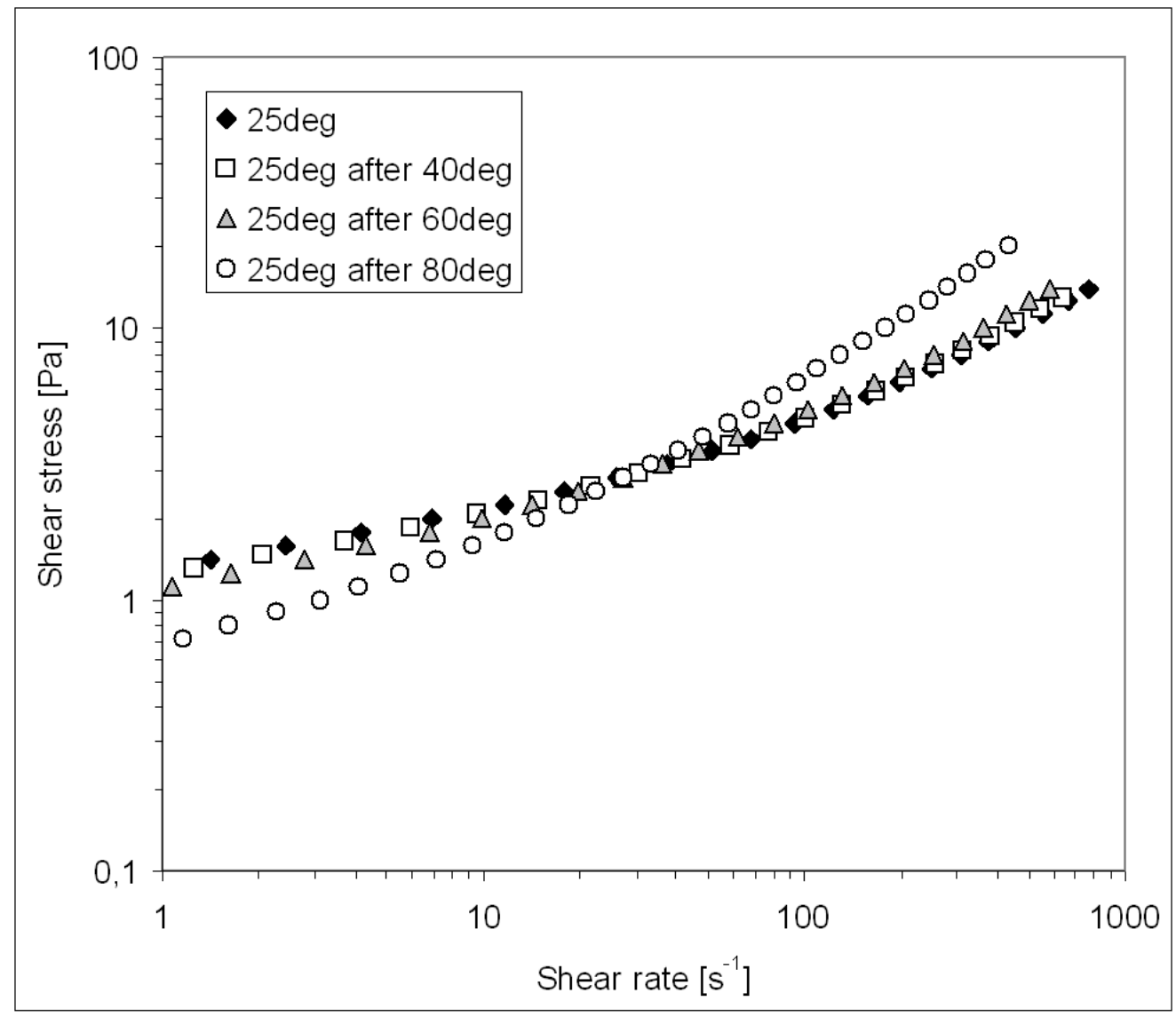

Figure 8: Flow curve of the $3.2 \%$ digested sludge at $25^{\circ} \mathrm{C}$ after being heated to 40.60 and $80^{\circ} \mathrm{C}$.

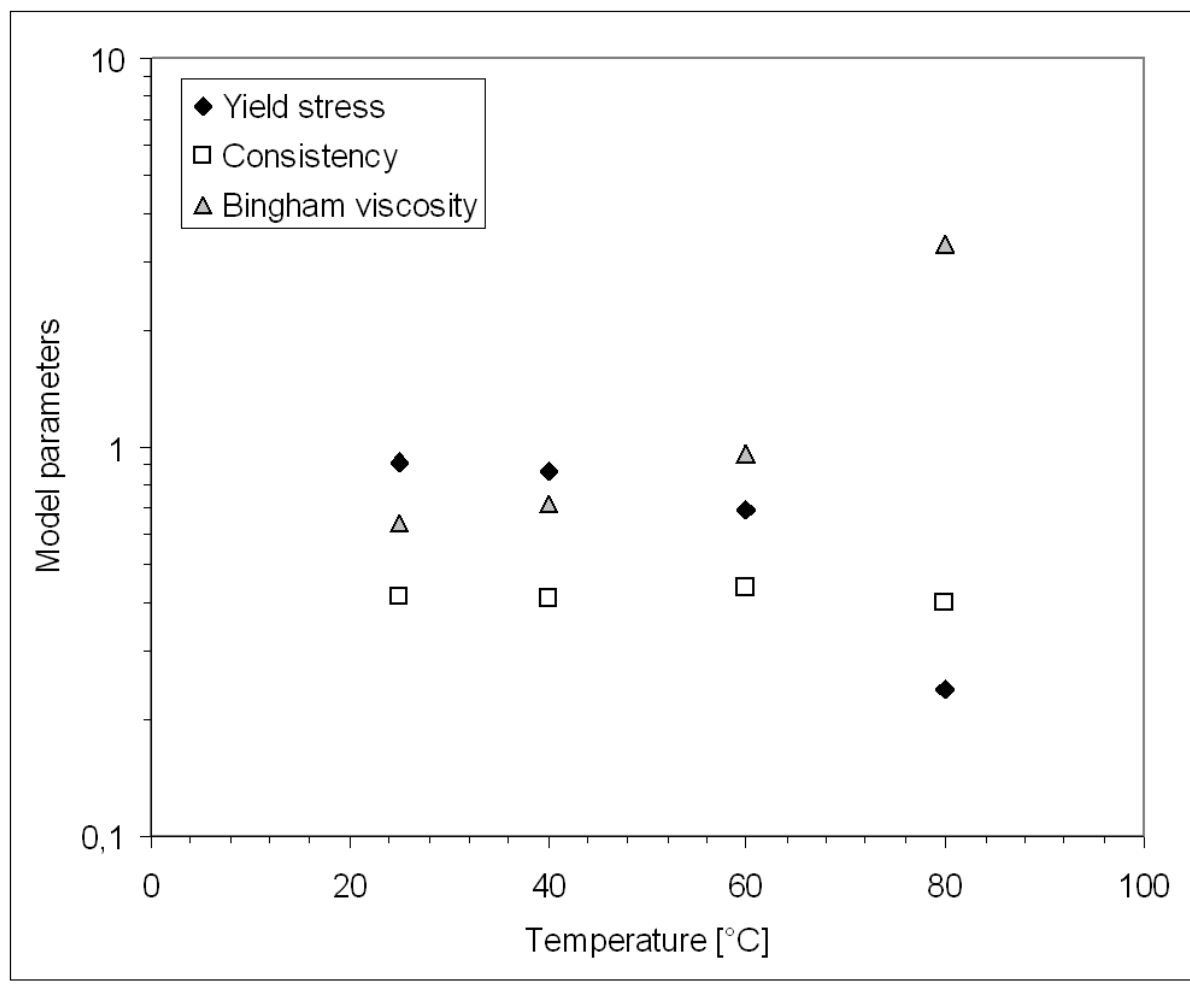

Figure 9: Evolution of the parameters of Equation (2) for the $3.2 \%$ sludge at $25^{\circ} \mathrm{C}$ with respect to its thermal history 


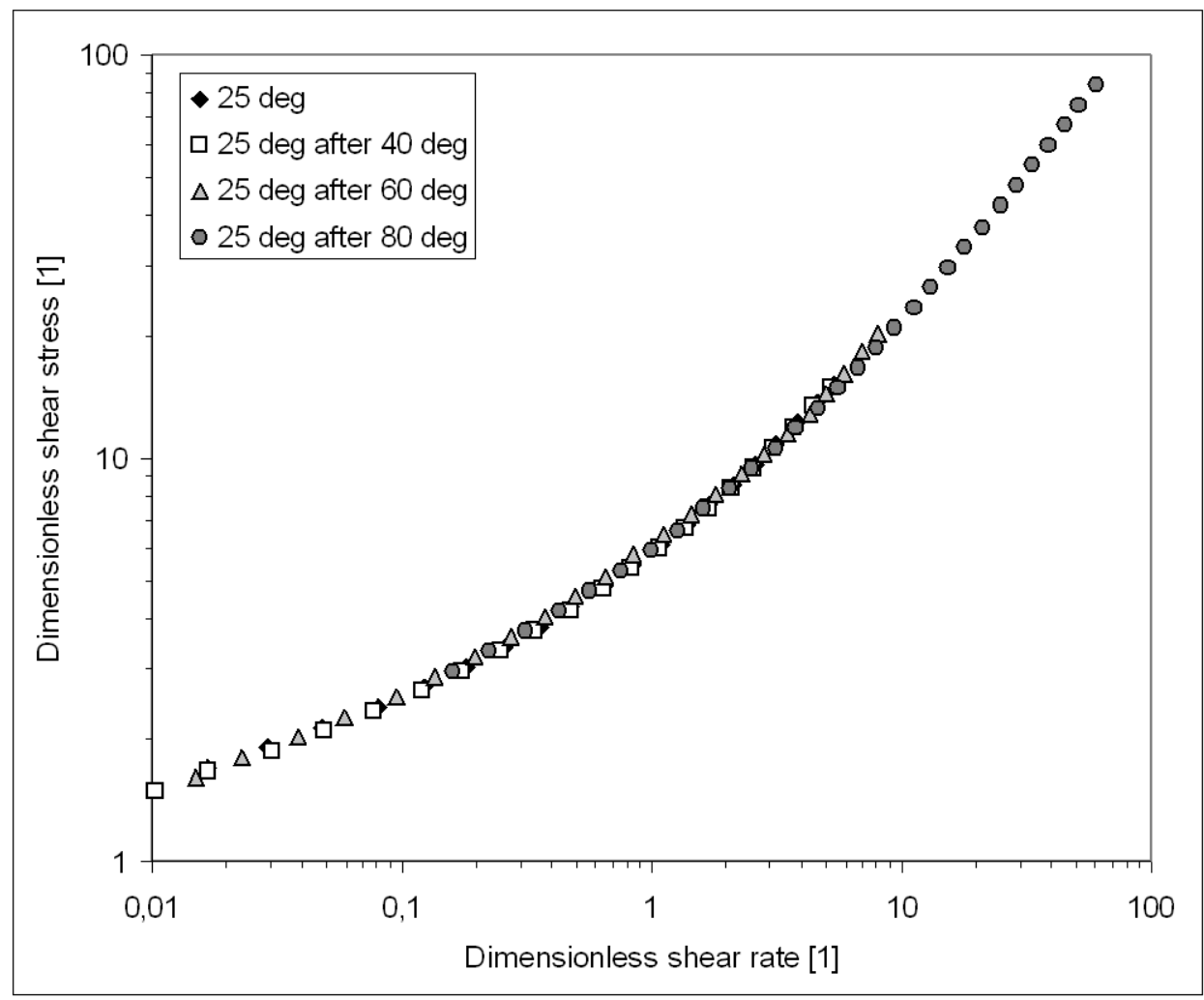

Figure 10: Dimensionless flow curve of the $3.2 \%$ digested sludge at $25^{\circ} \mathrm{C}$ after being heated to 40.60 and $80^{\circ} \mathrm{C}$.

4

5

6

7

8 